\title{
Use or Misuse of Antibiotics in Pediatric Dentistry!!!
}

\author{
Monika K*, Poonacha KS, Kritika D, Rameshwari R and Shamsudin K \\ Department of Pedodontics and Preventive Dentistry, KM Shah Dental College and \\ Hospital, India
}

*Corresponding author: Monika Khoja, Department of Pedodontics and Preventive

\section{Review Article \\ Volume 4 Issue 2}

Received Date: April 04, 2019

Published Date: April 29, 2019

DOI: 10.23880 /oajds-16000224 Dentistry, KM Shah Dental College and Hospital, Gujarat, India, Tel : +919429299994; Email: monikakhoja@gmail.com

\begin{abstract} of antibiotics is advised for Pediatric age group.

Keywords: Antibiotics use; Misuse; Intracanal medicament; Pediatric age; Dose
\end{abstract}

In children, unjustified used of antibiotic is very common; specifically for ear and dental infections. Antibiotics are used in dentistry for two for most reasons: to control oral infection and to reduce systemic bacteremia. Antibiotics are universally prescribed by dentists, uses and mishandlings of these drugs should be accustomed to all committed clinicians. Physiological as well as the correct dosage of the medicine is equally important. In this article, the dental conditions and appropriate antibiotics are mentioned. The intracanal medicaments are mentioned. The appropriate use

\section{Introduction}

Accurate use of antibiotics depends upon alert diagnosis of the patient's oral disease, satisfactory understanding of the patient's systemic ailment, and comprehensive understanding of antibiotic therapy. While countless articles give the impression in the references each year regarding, one antibiotic or another, there is insufficiency of comprehensive information regarding the use of antibiotics in pediatric dentistry [1]. However, in children, microbial resistance to antibiotics is a well- recognized and is a serious worldwide health alarm $[2,3]$.

\section{Physiological Considerations for Pediatric Patients}

- Unlike adults, children are constantly growing and developing. This fact should be taken into account whenever any drugs are given to children, there are large differences in body surface area as well as hepatic and renal functions depending on age.
- The body of a pediatric patient is not simply a miniature version of adult.

- Child physiology and anatomy significantly differ from adult.

- Route and rate of drug administration, dosage, onset and duration of action, and possible toxicity all are influenced by the unique physiology of childhood [1].

a) Absorption: Various host factors affect the absorption of drug. Example-existing surface area, gastric and duodenal $\mathrm{pH}$, gastric emptying time, size of bile salt pool, bacterial colonization of gastrointestinal tract, presence and extent of underlying diseases influences drug absorption $[4,5]$.

b) Distribution: Many factors should be taken into consideration - Body fat is lower in children so the distribution of fat-soluble drug is limited and half-life of drug would be shorter. Level of plasma proteins is lower, so level of free drug would be more. Blood brain permeability in children is also more $[4,5]$.

c) Metabolism: Liver and kidney are the major organs liable for metabolism of drugs [4]. 


\section{Open Access Journal of Dental Sciences}

d) Excretion: The development and maturation of the glomerular filtration rate is important in determining the appropriate drug dosage $[4,5]$.

\section{Which Factors Should Be Considered While Prescribing Drugs for Pediatric Age Group??}

Route of Administration: The oral route (tablets, capsules, syrup) is preferred for pediatric patients. Other routes are I.V. and I.M., in severe cases or in the emergency situation I.V. route is preferred. Clear instructions should be given to the patient and parents drugs are taken before OR after the meal. For Example: Antibiotics such as penicillin G, ampicillin, cloxacillin, lincomycin, drug immersion is pointedly dwindled when given with foodstuff. Tetracycline should not be prescribed with milk, dairy products or food stuffen closing calcium and magnesium, which interfere with absorption of drug. Liquid formulations are available for most preparations and should be used, if the young patients are incapable to swallow the tablets or capsules [6].

Age: Paediatric patients are allocated into subcategories (preterm newborns, term newborns, infants, toddlers, children and adolescents) and the dose is selected based on child's age.

Drawback of this method: It does not take into account the deviations due to developmental growth that occur within each age cluster [7].

For example: The hepatic metabolic ability of a 5-yearold child is absolutely different from that of 1 or 2 years old.

Weight: Currently, studies advocate that, one of the reliable way to establish how dose relates to body weight is through the use of nonlinear relationships, such as, for example, allometric scaling.

$\mathrm{P}$ child $=\mathrm{P}$ adult* $(\mathrm{WT} / 70) \mathrm{x}$

Where, $\mathrm{P}=$ parameter of interest,

$\mathrm{WT}=$ Bodyweight of the individual child and

$\mathrm{X}=$ The allometric exponent [8]

Body Surface Area: Differentiation of the dose from adults can also be performed by normalization, based on body surface area (BSA), under the supposition that metabolic processes in humans are constant when expressed as a function of BSA. A few short comings limit the submission of this method: Strain in calculating BSA (due to the complexity and inaccuracy of the formulae that can be used) and the predisposition to overdose pediatric population [9].

Medical Conditions: All the medical conditions and ongoing medicines should be taken into consideration.
Taste, Odour \& Colour of the Drug: Medicine with bad taste, may not be palliative by child. So, the taste and color should be pleasant.

\section{Antibiotics for Pediatric Patients}

Goal for prescribing antibiotic: To use the smallest amount of the antibiotic which is the most effective against the microorganism causing the infection [10].

Selection (Types): In dental conditions, it is desirable to choose an agent with a specific spectrum of activity with as few adverse effects as possible. The guaranteed way to govern which antibiotic will be most effective is to isolate the offending organism with culture and sensitivity tests of the disease-ridden area. However, it is not always possible to secure an uncontaminated sample from the diseased part, particularly when it is located in the mouth (with its own endemic diverse flora) $[11,12]$.

Local and systemic antibiotics in pediatric dentistry: During endodontic treatment and sever trauma, antibiotics can be given systemically (orally and/or parenterally) or locally (i.e. intra-dentally via irrigants and medicaments). Due to the possible risk of contrary effects by systemic submission, and the ineffectiveness of systemic antibiotics in necrotic pulpless teeth and periradicular tissues, the local submission of antibiotics may be a more effective approach. The complete eradication of bacteria from the root canal system by instrumentation unaccompanied is not achieved Card, et al. 2002. Therefore, additional methods - use of antibiotic solutions and medicaments are required [13]. It can be arbitrarily divided into irrigants, rinses and interappointment medicaments:

\section{Which agents can be used in Pediatric dentistry?}

Tetracycline: In endodontics, tetracyclines have been used to remove the smear layer (Haznedaroglu \& Ersev 2001), and as intracanal medicaments (Molander \& Dahlen 2003).

Bio Pure (MTAD): (Mixture of Tetracycline, Acid and Detergent).

Ledermix paste: Ledermix is a glucocorticosteroidantibiotic compound, but not collectively used in pediatric dentistry.

Triple antibiotic paste: Because of the complexity of root canal infections, the use of a single antibiotic may not be effective. A combination of antibiotics may decrease the development of resistant bacterial strains. Takushige, et al. estimated the usefulness of a poly antibiotic paste consisting of ciprofloxacin, metronidazole and minocycline, on the scientific outcome of so-called 'Lesion Sterilization and Tissue Repair' (LSTR) therapy in 


\section{Open Access Journal of Dental Sciences}

primary teeth with periradicular lesions. Minocyclin is not used now a days as it leads to discoloration of tooth. As an irrigating solution amoxicillin can also be used [13].

\section{Antibiotics and Dental Conditions}

\section{Pulpitis/Apical Periodontitis/Draining Sinus Tract/Localized Intra-Oral Swelling}

Antibiotic therapy is not indicated typically if the dental infection is confined within the pulpal tissue or the immediate surrounding tissue (acute symptoms of pulpitis, treatment (i.e., pulpotomy, pulpectomy, or extraction-without any systemic problem) [12,13]. In advanced non-odontogenic bacterial infections such as staphylococcal mucositis, tuberculosis, gonococcal stomatitis, and oral syphilis - systemic antibiotics are indicated. If suspected, it is best to refer patients for culture, biopsy, or other laboratory tests, so that definitive treatment can be provided [13].

\section{Acute Facial Swelling of Dental Origin}

Extra oral swelling or cellulitis subordinate to an odontogenic infection should receive speedy dental attention. In most circumstances, immediate surgical intervention is appropriate [14]. Intravenous antibiotic therapy mostly indicated [12,3]. Penicillin remains the first hand choice for odontogenic infections; additional adjunctive antimicrobial therapy (i.e., metronidazole) can be given where there is anaerobic bacterial involvement [15].

\section{Dental Trauma}

Systemic antibiotics are recommended for avulsed permanent incisors with an open or closed apex. Tetracycline (Doxycycline twice daily for seven days) is the drug of choice, but child's age should be taken into the consideration because it can lead to discoloration in the developing permanent dentition. Penicillin $\mathrm{V}$ or amoxicillin can be given as an alternative $[16,17]$. The topical antibiotics has shown some potential to tempt pulpal revascularization in immature non-vital traumatized teeth $[14,15]$.

In the case of laxative injuries in the primary dentition, antibiotics usually are not indicated. Antibiotics can be defensible in cases of concomitant soft tissue injuries $[14,18]$.

\section{Pediatric Periodontal Diseases}

a) Dental plaque-induced gingivitis does not entail antibiotic therapy. b) Aggressive periodontal diseases may require adjunctive antimicrobial therapy in combination with localized treatment [19].

c) Periodontal diseases associated with systemic disease (e.g., severe congenital neutro-penia, Papillon-Lefevre syndrome, leukocyte adhesion deficiency), the immune system is unable to control the growth of periodontal pathogens and, in selected cases, treatment may involve antibiotic therapy $[19,20]$.

\section{Salivary Gland Infections}

Many salivary gland infections, following confirmation of bacterial etiology, will respond favorable to antibiotic therapy. Acute bacterial parotitis - hospital acquired and community acquired- Both can be treated with antibiotics. Hospital acquired usually requires intravenous antibiotics; oral antibiotics are for community acquired. For acute bacterial submandibular sialadenitis and chronic recurrent submandibular sialadenitis, antibiotic therapy is encompassed as part of the treatment [21].

\section{Dose Calculation for Children}

The most common method - normalize the adult dose by body weight (i.e.mg kg-1), assuming a linear affiliation between weight and dose. This means that the dose doubles with a twofold increase in the weight of a child [9].

Various formulas were given for the calculation of dose. a) cler's rule: Childs Dose $=$ Adult Dose $X$ (Weight $\div 150$ )

b) Young's Rule: Adult Dose X (Age $\div($ Age +12$))=$ Child's Dose.

c) Dosage based on weight. The calculation is very simple and easy to perform. However, you must pay close attention to whether the dosage has been prescribed per Kg or Lbs.

\section{Dosage and Duration Guidelines}

For commonly used antibiotics in children:

Amoxicillin: Usual oral dosage for 1-3 Children $>3$ months - 125-250 mg every 8 hours and adults weight upto the $40 \mathrm{~kg}$ is $250-500 \mathrm{mg}$ every 8 hours OR $500-875$ mg every 12 hours.

For Endocarditis prophylaxis $50 \mathrm{mg} / \mathrm{kg}$ (maximum $2 \mathrm{~g}$ ) can be given, 30-60 minutes before procedure.

Amoxicillin clavulanate potassium: Usual oral dosage, based on amoxicillin component, for Children $>3$ months of age up to $40 \mathrm{~kg}: 25-45 \mathrm{mg} / \mathrm{kg} /$ day: doses divided every 12 hours (suspension or chewable tablet) for Children $>40 \mathrm{~kg}$ and adult the dose is $500-875 \mathrm{mg}$ every 12 hours.(tablet) 


\section{Open Access Journal of Dental Sciences}

Azithromycin: Usual oral dosage, for Children $>6$ months up to 16 years: $5-12 \mathrm{mg} / \mathrm{kg} 1$ time/day (maximum 500 $\mathrm{mg} /$ day) OR $30 \mathrm{mg} / \mathrm{kg}$ as a single dose (max. $1500 \mathrm{mg}$ ). Children $>16$ years and adults: $250-600 \mathrm{mg} 1$ time/day OR 1-2 $\mathrm{g}$ as a single dose.

Indication: As Endocarditis prophylaxis, $15 \mathrm{mg} / \mathrm{kg}$ (maximum 500 $\mathrm{mg}$ ) 30-60 minutes before procedure is given. Used for patients with Type I allergy to penicillin and/or cephalosporin antibiotics.

Metronidazole: For periodontal disease, including necrotizing ulcerative gingivitis, $250 \mathrm{mg}$ metronidazole is given for every 6-8 hours for 10 days OR $500 \mathrm{mg}$ is given for every 8 hours for 8 days to adults. For aggressive oral infections-used in amalgamation with amoxicillin: $250 \mathrm{mg}$ 3 times/day with amoxicillin (250-375 mg 3 times/day) for 7-10 days [22].

\section{Summary}

Antibiotics should be prescribed in very judicious way. The latest AAPD guidelines should be followed. Dentist must know the ideal dosage of drugs. Antibiotics should be give or dosage calculation should be done according to the weight and age of the child- most recommended method.

\section{References}

1. Oberoi SS, Dhingra C, Sharma G, Sardana D (2015) Antibiotics in dental practice: How justified are we. Int Dent J 65(1): 4-10.

2. Gregoire C (2010) How are odontogenic infections best managed? J Can Dent Assoc 76(2): 114-116.

3. Thikkurissy S, Rawlins JT, Kumar A, Evans E, Casamas-simo PS (2010) Rapid treatment reduces hospitalization for pediatric patients with odontogenic-based cellulitis. Am J Emerg Med 28(6): 668-672.

4. Wood M, Wood AJ (2015) Changes in plasma binding and alpha 1-acid glycoprotein in mother and newborn infant. Clin Pharmacol Ther 29(4): 522-526.

5. Reed MD, Besunder JB (1989) Developmental pharmacology ontogenic basis of dug deposition. Pediatr Clin North Am 36(5): 1053-1074.

6. Madugula KS, Kasipathi MR. Antibiotic and antimicrobial use in treating pulpal infection. Dentistry Today 29(1): 102,106,107.
7. Johnson TN, Rostami-Hodjegan A, Tucker GT (2006) Prediction of the clearance of eleven drugs and associated variability in neonates, infants and children. Clin Pharmacokinet 45(9): 931-956.

8. Holford NH (1996) A size standard for pharmacokinetics. Clin Pharmacokinet 30(5): 329332.

9. Meine Jansen CF (2005) Treatment of symptomatic congenital cytomegalovirus infection with valganciclovir. J Perinat Med 33(4): 364-366.

10. Wagner (2015) Relevant pharmacokinetics of antimicrobial drugs. Med Clin North Am 58: 479-492.

11. Sanders B, Sanger RG (1979) Infections, in Pediatric Oral and Maxillofacial Surgery. In: Sanders B, (Eds.), St. Louis: CV. MosbCy, pp: 182-220.

12. Maestre V (2004) Treatment options in odontogenic infection. Med Oral Patol Oral Cir Bucal 9(S): 19-31.

13. Keenan JV, Farman AG, Fedorowicz Z, Newton JT (2006) A Cochrane system review finds no evidence to support the use of antibiotics for pain relief in irreversible pulpitis. J Endod 32(2): 87-92.

14. Johri A, Piecuch JF (2011) Should teeth be extracted immediately in the presence of acute infection? Oral Maxillofac Surg Clin North Am 23(4): 507-511.

15. Flynn T (2011) What are the antibiotics of choice for odonto-genic infections, and how long should the treatment course last? Oral Maxillofac Surg Clin N Am 23(4): 519-536.

16. Andreasen JO, Andreasen FM (2007) Textbook and Color Atlas of Traumatic Injuries to the Teeth. In: $4^{\text {th }}$ (Edn.), Copenhagen, Denmark: Blackwell Munksgaard, pp: 461,478-488.

17. Andersson L, Andreasen JO, Day P, Heithersay G, Trope M, et al. (2012) International Association of Dental Traumatology Guidelines for the management of traumatic dental injuries: 2-Avulsion of permanent teeth. Dent Traumatol 28(2): 88-96.

18. (2013) American Academy of Periodontology Research, Science and Therapy Committee. Periodontal diseases of children and adolescents. J Periodontol 74: 1696-704.

19. Schmidt JC, Wlater C, Rischewski JR, Weiger R (2013) Treatment of periodontitis as a manifestation of 


\section{Open Access Journal of Dental Sciences}

neutropenia with or without systemic antibiotics: A systematic review. Pediatr Dent 35(2): 54-63.

20. Carlson ER (2009) Diagnosis and management of salivary gland infections. Oral Maxillofac Surg Clin N Am 21(3): 293-312.

21. (2017) AAPD Handbook.
22. Pavan KK, Mamta K, Udaya KP, Shilpa MR, Neha Prashar (2013) Antibiotic prescribing habits of Dental Surgeons in Hyderabad city, India, for pulpal and Periapical Pathologies: A survey. Advances in pharmacological sciences. 